\title{
Low-Volume Intense Exercise Elicits Post-exercise Hypotension and Subsequent Hypervolemia, Irrespective of Which Limbs Are Exercised
} Matthew J. Graham ${ }^{1}$, Samuel J. E. Lucas $^{2,3}$, Monique E. Francois ${ }^{1}$, Stasinos Stavrianeas ${ }^{4}$,
Evelyn B. Parr ${ }^{1}$, Kate N. Thomas ${ }^{1,5}$ and James D. Cotter ${ }^{1 *}$

\begin{abstract}
${ }^{1}$ School of Physical Education, Sport and Exercise Sciences, University of Otago, Dunedin, New Zealand, ${ }^{2}$ Department of Physiology, University of Otago, Dunedin, New Zealand, ${ }^{3}$ School of Sport, Exercise and Rehabilitation Sciences, University of Birmingham, Birmingham, UK, ${ }^{4}$ Department of Exercise Science, Willamette University, Oregon, USA, ${ }^{5}$ Department of Surgical Sciences, Dunedin School of Medicine, University of Otago, Dunedin, New Zealand
\end{abstract}

\section{OPEN ACCESS}

Edited by: Johnny Padulo,

University eCampus, Italy

Reviewed by:

Naoto Fujii

University of Ottawa, Canada

Domenico Martone, University of Naples "Parthenope",

Italy

*Correspondence:

James D. Cotter

jim.cotter@otago.ac.nz

Specialty section:

This article was submitted to

Exercise Physiology,

a section of the journal

Frontiers in Physiology

Received: 31 March 2016 Accepted: 17 May 2016

Published: 31 May 2016

Citation:

Graham MJ, Lucas SJE, Francois ME, Stavrianeas $S$, Parr EB, Thomas KN and Cotter JD (2016) Low-Volume Intense Exercise Elicits Post-exercise

Hypotension and Subsequent Hypervolemia, Irrespective of Which Limbs Are Exercised. Front. Physiol. 7:199. doi: 10.3389/fphys.2016.00199
Introduction: Exercise reduces arterial and central venous blood pressures during recovery, which contributes to its valuable anti-hypertensive effects and to facilitating hypervolemia. Repeated sprint exercise potently improves metabolic function, but its cardiovascular effects (esp. hematological) are less well-characterized, as are effects of exercising upper versus lower limbs. The purposes of this study were to identify the acute $(<24 \mathrm{~h})$ profiles of arterial blood pressure and blood volume for (i) sprint intervals versus endurance exercise, and (ii) sprint intervals using arms versus legs.

Methods: Twelve untrained males completed three cycling exercise trials; 50-min endurance (legs), and 5*30-s intervals using legs or arms, in randomized and counterbalanced sequence, at a standardized time of day with at least 8 days between trials. Arterial pressure, hemoglobin concentration and hematocrit were measured before, during and across $22 \mathrm{~h}$ after exercise, the first $3 \mathrm{~h}$ of which were seated rest.

Results: The post-exercise hypotensive response was larger after leg intervals than endurance (AUC: $7540 \pm 3853$ vs. $3897 \pm 2757 \mathrm{~mm} \mathrm{Hg} \cdot \mathrm{min}, p=0.049$, 95\% Cl: 20 to 6764), whereas exercising different limbs elicited similar hypotension (arms: $6420 \pm 3947 \mathrm{~mm} \mathrm{Hg} \cdot \mathrm{min}, p=0.48, \mathrm{Cl}:-1261$ to 3896$)$. In contrast, arterial pressure at $22 \mathrm{~h}$ was reduced after endurance but not after leg intervals $(-8 \pm 8 \mathrm{vs} .0 \pm 7 \mathrm{~mm}$ $\mathrm{Hg}, p=0.04, \mathrm{Cl}: 7 \pm 7)$ or reliably after arm intervals $(-4 \pm 8 \mathrm{~mm} \mathrm{Hg}, p=0.18$ vs. leg intervals). Regardless, plasma volume expansion at $22 \mathrm{~h}$ was similar between leg intervals and endurance (both $+5 \pm 5 \%$; $\mathrm{Cl}$ : -5 to $5 \%$ ) and between leg and arm intervals (arms: $+5 \pm 7 \%, \mathrm{Cl}:-8$ to $5 \%$ ).

Conclusions: These results emphasize the relative importance of central and/or systemic factors in post-exercise hypotension, and indicate that markedly diverse exercise profiles can induce substantive hypotension and subsequent hypervolemia. At least for endurance exercise, this hypervolemia may not depend on the volume of post-exercise hypotension. Finally, endurance exercise led to reduced blood pressure the following day, but sprint interval exercise did not.

Keywords: blood pressure, exercise training, plasma volume, HIIT, sprint exercise, arm exercise 


\section{INTRODUCTION}

Good cardiovascular function is important for health and for physical capabilities. A high blood volume and low resting blood pressure are both integral aspects of good cardiovascular function, and both are sensitive to endurance exercise training (Sawka et al., 2000). A principal mechanism by which blood volume increases following exercise appears to be through postexercise hypotension (PEH) (Nagashima et al., 1999; Hayes et al., 2000). PEH is caused largely by a decreased vascular resistance, which is mediated by both central and peripheral factors and interactions between them-for example, by input from muscle afferents acting centrally to downregulate sympathetic control of peripheral resistance, and also impairing transmission of norepinephrine from sympathetic nerves within the resistance vessels (Halliwill et al., 2013). While such mechanisms have been resolved recently, some aspects of $\mathrm{PEH}$ remain less clear, including the dose-vs.-response relation of $\mathrm{PEH}$ to the ensuing expansion of plasma volume, and the impact of different exercise parameters (i.e., exercise duration, intensity, and esp. type) on both of these responses. Each exercise parameter will likely have characteristic effects on central and peripheral mediators of $\mathrm{PEH}$ (e.g., higher intensity of exercise disproportionately increases sympathetic activation but also humoral mediators of vasodilation and its attenuation), so they could be expected to have different effects on both $\mathrm{PEH}$ and exercise-induced hypervolemia.

Whether exercise intensity affects the magnitude of $\mathrm{PEH}$ seems unresolved (see: Eicher et al., 2010; Lacombe et al., 2011; Halliwill et al., 2013). For example, sustainable exercise performed at higher intensity (75 vs. 50 or $30 \% \dot{\mathrm{VO}}_{2} \max$ ) elicits larger and longer PEH (Forjaz et al., 2004), which may not be attributable to the higher volume of exercise because incremental exercise to $100 \% \mathrm{VO}_{2}$ max has also been found to produce a larger $\mathrm{PEH}$ than did $30 \mathrm{~min}$ of exercise at 40 or $60 \% \dot{\mathrm{VO}}_{2}$ max, while they had equivalent effect (Eicher et al., 2010). Whereas, repeated bouts of unsustainable exercise (usually $\geq 85 \% \dot{\mathrm{VO}}_{2} \max$ ), i.e., high-intensity interval exercise, have been shown to induce $\mathrm{PEH}$ equivalent to that following typically-sustainable exercise intensities $\left(\sim 60-65 \% \dot{\mathrm{VO}}_{2} \max \right)$, both when matched for exercise volume (Lacombe et al., 2011), and when performed as maximal-effort sprint intervals and thus involving much lower volume (Rossow et al., 2010). The lack of consistency in findings seems unatttributable to individual factors such as aerobic fitness or resting blood pressure (Lacombe et al., 2011; Halliwill et al., 2013). Nonetheless, PEH facilitates post-exercise plasma restoration (Hayes et al., 2000; Jones et al., 2007) and stimulates hypervolemia (Nagashima et al., 1999, 2000), but the hypervolemic effects of sprint intervals remain largely unknown. This lack of hematological information is in contrast to the wealth of findings showing rapid and marked

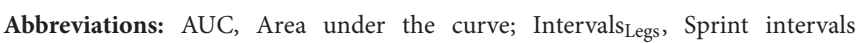

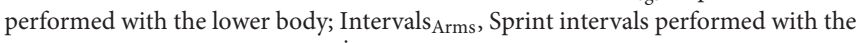
upper body; TnT, Troponin $\mathrm{T}$; $\dot{\mathrm{VO}}_{2}$ max, maximal aerobic power; kg, kilogram; $\mathrm{W}$, watts; $\mathrm{mL}$, milliliters; $\mu \mathrm{L}$, microliters; $\mathrm{mm}$, millimeter; rpm, revolutions per minute; MAP, mean arterial blood pressure; SBP, systolic arterial blood pressure; DBP, diastolic arterial blood pressure; $\mathrm{mOsmol} \cdot \mathrm{kg}^{-1}$, milliosmoles per kilogram of water. improvements in several metabolic functions following sprint interval training (Gibala et al., 2006; Burgomaster et al., 2008; Gibala and Mcgee, 2008), and limited knowledge on vascular effects (Rakobowchuk et al., 2008; Whyte et al., 2010). A more complete understanding of the physiological effects of highintensity interval training, including sprint interval training, is required for practical reasons, i.e., because a minority of people obtain their currently-recommended doses of sustainable exercise per day for health (SPARC, 2008; Tucker et al., 2011). If similar cardiovascular benefits can also be obtained from brief intervals, this would provide more flexibility and variety to exercise prescription, at least for healthy and younger individuals.

The extent to which PEH and expansion of blood volume are stimulated by the size and/or gravitational dependency of the vasculature used in the preceding exercise bout have seldom been examined, and may be an important factor for driving $\mathrm{PEH}$ (Miles et al., 1983; de Almeida et al., 2010). The differences in the size and location of the muscle mass used between upper- and lower-body exercise provides one means to investigate whether limbs or muscle mass is important, while also having important practical ramifications (MacDonald et al., 2000; de Almeida et al., 2010). Many people exercise with their arms by choice for sport (kayakers) or for job requirements (laborers), while others are forced to due to other circumstances (paraplegia, orthopedic limitations). Gaining a better understanding of the potential cardiovascular benefits of such exercise becomes important in optimizing health and performance for such individuals.

Therefore, the purpose of the current study was to determine the roles of exercise intensity (endurance vs. interval training) and limb dependency (legs vs. arms) on the hemodynamic responses during exercise and especially during recovery $(<24$ h). We hypothesized that: (i) Endurance exercise performed with the lower body (cycling), and brief Intervals performed

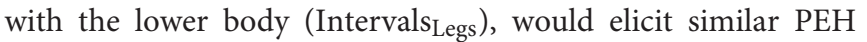
and subsequent increases in blood volume despite the five-fold difference in exercise volume completed, and; (ii) Intervals $s_{\text {Legs }}$ would elicit larger $\mathrm{PEH}$ and subsequent hypervolemia compared to intervals performed with the upper body (Intervals Arms) when performed at matched relative exertion (maximal voluntary intensity). As a secondary purpose, we examined Troponin $\mathrm{T}$ responses-as a specific marker of cardiac "damage"-to the disparate exercise profiles. Plasma concentrations of this marker rise in healthy individuals following both prolonged endurance exercise (e.g., a marathon) and intense endurance exercise (30min run) (Shave et al., 2005, 2010; Middleton et al., 2008). Although the Troponin release is thought to be physiological rather than pathological in exercise, little is known about the effect of different exercise parameters (intensity, duration, type) on its release. This study was therefore an opportunity to examine Troponin $\mathrm{T}$ release in healthy participants following unaccustomed exercise, as a measure of the cardiac stress involved in interval training.

\section{METHODS}

\section{Participants}

Twelve untrained males (mean \pm SD; age: $23 \pm 3$ years; body mass: $72.4 \pm 12.8 \mathrm{~kg}$, height: $174 \pm 8 \mathrm{~cm}, \mathrm{BMI}: 24.0 \pm 3.9 \mathrm{~kg} \cdot \mathrm{m}^{-2}$, 
maximal aerobic power: $\dot{\mathrm{V}} \mathrm{O}_{2}$ max: $44 \pm 8 \mathrm{~mL} \cdot \mathrm{kg}^{-1} \cdot \mathrm{min}^{-1}$ ) were recruited to the study, which was approved by the University of Otago Human Ethics Committee and conformed to the standards set by the Declaration of Helsinki. Untrained was classified as undertaking two or fewer 30-min exercise sessions per week in the previous 6 months. All participants were non-smokers and abstained from caffeine and alcohol for $24 \mathrm{~h}$ before, and throughout, each experimental trial. Participants were informed of the experimental procedures and possible risks before giving written informed consent.

\section{Experimental Protocol Design}

A Latin Square study design was used with a balanced crossover of conditions. All trials were at the same time of day and separated by an average of 2 weeks (range: $8-30$ days) to ensure adequate wash out. Participants underwent a familiarization session, in which initial screening was completed, and an incremental exercise test to exhaustion to determine their cycling $\mathrm{V}_{2} \max$ (see below). The Endurance exercise was set at a workload corresponding to $65 \% \dot{\mathrm{V}}_{2}$ max. Participants also conducted one 30-s interval for each of the Interval conditions to familiarize with the Intervals Legs $_{\text {and }}$ antervals $s_{\text {Arms }}$ protocols. In a following session, blood volume was measured using carbon monoxide dilution (Schmidt and Prommer, 2005), at least 1 week following $\dot{\mathrm{VO}}_{2}$ max determination and within 1 week before their first trial.

Participants' diet was standardized (i.e., provided to them) over the $15 \mathrm{~h}$ before and $22 \mathrm{~h}$ during each trial because protein intake is known to affect albumin synthesis and catabolism, and therefore plasma volume expansion (de Feo et al., 1992; Okazaki et al., 2009a,b). Participants were advised to avoid physical activity in the $24 \mathrm{~h}$ before and during each experimental trial (monitored using physical activity recall logs).

The $\dot{V} \mathrm{O}_{2}$ max test, undertaken to characterize the cohort and establish workrate for Endurance exercise, was undertaken on an electromagnetically-braked cycle ergometer (Velotron, RacerMate Inc, Seattle, USA). Participants warmed up for $5 \mathrm{~min}$ at a self-selected workrate, then undertook the following incremental protocol to exhaustion: Workrate started at 100 $\mathrm{W}$ and incremented by $33 \mathrm{~W}$ at 3-min intervals for four increments before ramping upward at $25 \mathrm{~W}$ per minute until voluntary exhaustion. Respiratory gases were sampled breath-bybreath (Cosmed Cardio Pulmonary Testing, CosmedSrl, Rome, Italy), and $\mathrm{VO}_{2}$ max was calculated from the highest 30$s$ averaged value. The Endurance exercise workrate was then determined by interpolating the steady-state $\dot{\mathrm{V}}_{2}$-to-workrate relation established from the first four stages of the test.

\section{Procedure for Each Trial}

A schematic of the basic testing procedure is shown in Figure 1. Participants arrived at the laboratory at 8:00 a.m. in a fasted state and were asked to void their bladder before height, body mass and urine specific gravity were measured. Thereafter, a flexible cannula was inserted into a suitable vein in the antecubital fossa

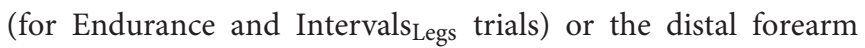
(for Intervals Arms $_{\text {S }}$ ). Participants sat in a standardized chair for
20 min before beginning baseline measurements, during which time a photoplethysmographic cuff was fitted on the index finger and a manual (auscultatory) cuff on the proximal segment of the non-cannulated arm. Baseline measurements were for 10min; consisting of beat-to-beat blood pressure for $8 \mathrm{~min}$ via photoplethysmography (see Measurements), 1 min of manual blood pressure recordings, then a blood sample during the 10th $\mathrm{min}$. Exercise then commenced at 09:10 a.m. for Endurance, and 09:35 a.m. for Interval sessions, such that recovery from exercise began at 10:00 a.m. for all sessions.

The exercise protocols were near replications of those described by Burgomaster et al. (2008). The Endurance protocol consisted of 50 min cycling at $65 \% \dot{\mathrm{VO}}_{2}$ max on a cycle ergometer (Velotron, RacerMateInc, Seattle, USA). $\dot{\mathrm{V}} \mathrm{O}_{2}$ was analyzed (Cosmed Cardio Pulmonary Testing, CosmedSrl, Rome, Italy) during the initial $5 \mathrm{~min}$ and work load adjusted if necessary to ensure that $65 \% \mathrm{~V}_{2}$ max was achieved; work load was fixed thereafter. Both interval protocols comprised $5 \times 30$ s maximal intervals separated by $4.5 \mathrm{~min}$ of active recovery. The Intervals Legs $_{\text {sere }}$ performed on the same ergometer as Endurance, against a resistance of $0.075 \mathrm{~kg} \cdot \mathrm{kg}$ body mass ${ }^{-1}$. The Intervals $_{\text {Arms }}$ protocol was performed on the same ergometer with a custom adaptation for arm-cranking, and was against a resistance $0.0375 \mathrm{~kg} \cdot \mathrm{kg}$ body mass ${ }^{-1}$. Participants were verbally encouraged to continue pedaling/cranking as fast as possible throughout each interval to achieve maximal effort. During the 4.5-min recovery period between intervals, participants remained on the bike (or seated for arm crank) and were permitted to cycle at a low cadence against light resistance $(30 \mathrm{~W}$ for Intervals $_{\text {Legs }}$ and $15 \mathrm{~W}$ for Intervals $_{\text {Arms }}$ ) to limit venous pooling, sensations of light-headedness or nausea (Burgomaster et al., 2008). Exercise was terminated if participants showed signs of distress or inappropriate physiological responses (e.g., vomiting or severe nausea). Air velocity was $2.2 \mathrm{~m} \cdot \mathrm{s}^{-1}$, generated using a large-diameter fan, and the exercise and rest were in temperate conditions $\left(21 \pm 1^{\circ} \mathrm{C}, 45 \pm 7 \%\right.$ relative humidity) to limit effects of heat stress on PEH (Halliwill et al., 2013).

For recovery, within $1 \mathrm{~min}$ of finishing exercise, participants were moved to a chair (within $1 \mathrm{~m}$ of ergometer) and seated in a standardized position, in which they remained for $3 \mathrm{~h}$. Following $3 \mathrm{~h}$, participants were allowed to leave the laboratory and undertake their daily routine, without any strenuous physical activity (i.e., necessary walking for normal daily activities (e.g., to get to lectures) was permitted). Participants then returned to the laboratory at 18:00 $\mathrm{h}$ that evening (post prandial) and 08:00 the next morning (fasted) for further measurements of blood pressure (auscultatory) and blood constituent concentrations following 20-min seated rest. Dinner and breakfast, respectively, were supplied following these measurement periods.

\section{Measurements}

Blood pressure was measured beat-to-beat using finger photoplethysmography (Finometer, Finapress Medical Systems, The Netherlands) at baseline and throughout the initial $3 \mathrm{~h}$ following exercise. The participant's hand rested on the armrest 


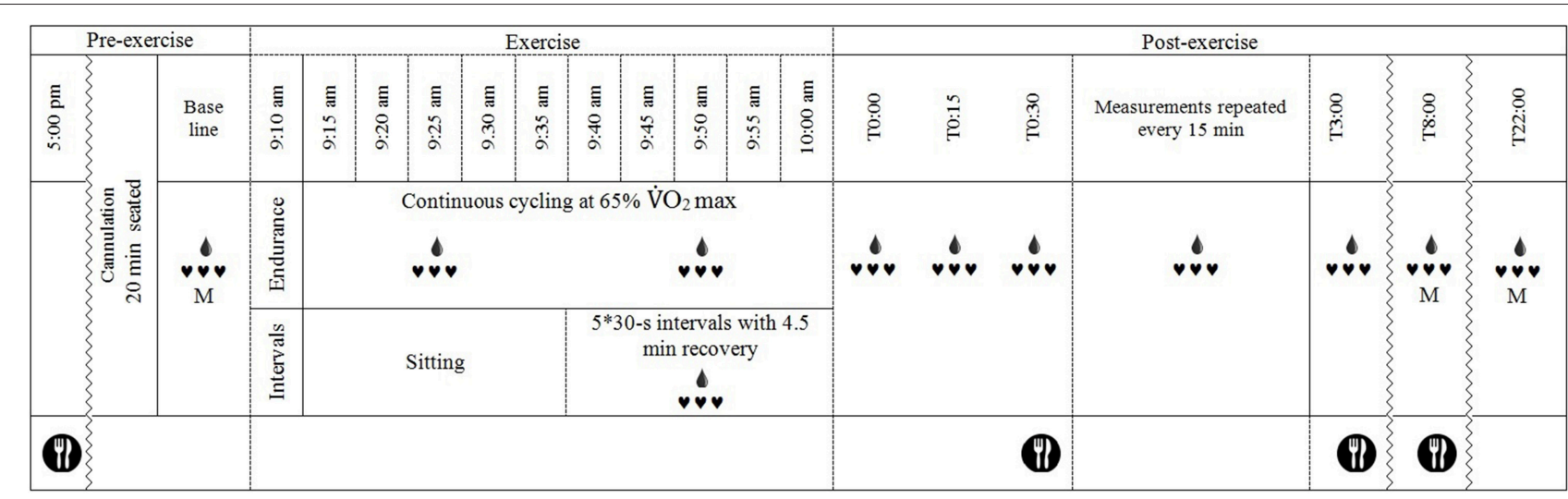

FIGURE 1 | Schematic of the experimental timeline. $\boldsymbol{v} \mathbf{v}$, continuous heart rate and beat-to-beat blood pressure recordings, M, manual blood pressure measurement; blood sample drawn (every 15 min after exercise except at T2:45); and standardized meal fed to participants.

of a chair for all measurements (including 8 and $22 \mathrm{~h}$ postexercise measures). Blood pressure was recorded for $5 \mathrm{~min}$ every $15 \mathrm{~min}$ in this 3 -h period, then averaged across the middle $3 \mathrm{~min}$. Photoplethysmography data were sampled at $200 \mathrm{~Hz}$ and converted to digital recordings (PowerLab/16SP ML795; ADInstruments, Dunedin, New Zealand) for storage to computer and analysis offline (Chart v7.3, ADInstruments). Auscultatory measurements were made using Korotkoff sounds (Pickering et al., 2005) at baseline, and 8 and $22 \mathrm{~h}$ following exercise. Measurement was in duplicate, 1 min apart, by the same experienced operator, using an aneroid sphygmomanometer (certified desk type, CE 0483, China) and stethoscope (Littmann Classic II, USA).

\section{Blood Constituents}

Venous blood samples $(4 \mathrm{~mL})$ were collected, without stasis, through the cannula (22 gauge, Teflon) into tubes containing EDTA-anti-coagulant, at baseline, immediately after exercise and at each 15-min interval throughout the initial $3 \mathrm{~h}$ following exercise. At 8 and $22 \mathrm{~h}$ following exercise, venous samples were obtained via venapuncture, without stasis. Hematocrit and hemoglobin concentration were measured from each sample immediately for calculation of changes in plasma volume, using the method outlined by Strauss et al. (1951). Hematocrit was measured from duplicate $75-\mu \mathrm{L}$ capillary tubes, after centrifugation at $3500 \mathrm{rpm}$ for $10 \mathrm{~min}$ (IEC Micro CL 17 centrifuge, Germany), to an accuracy of $0.1 \mathrm{~mm}$, using metric calipers. Hematocrit was corrected for trapped plasma and whole-body hematocrit (Chaplin and Mollison, 1952; Chaplin et al., 1953). The hemoglobin concentration was measured in duplicate using the modified methemoglobin reaction method (HemoCue Hb 201+, Ängelholm, Sweden). Remaining blood was immediately centrifuged at $4^{\circ} \mathrm{C}$, after which plasma was stored at $-80^{\circ} \mathrm{C}$ for later batch analysis of albumin, total protein, Troponin $\mathrm{T}$ and osmolality. Plasma albumin and total protein at baseline, $0,3,8$ and $22 \mathrm{~h}$ following exercise were analyzed in duplicate using automated spectrophotometry (Cobas c 111, Roche Instrument Centre, Switzerland). Plasma Troponin $\mathrm{T}$
(TnT) was analyzed at baseline, $0,3,8$, and $22 \mathrm{~h}$ following exercise using the Roche high-sensitivity assay (Cobas 6000 Analyzer, Roche Diagnostics GmbH, Mannheim), the basis of which is an electrochemilunescence immunoassay using two monoclonal antibodies specific for cardiac TnT. The upper reference limit for this assay is $14 \mathrm{ng} \cdot \mathrm{L}^{-1}$, as this represents the 99th centile of a healthy population (Thygesen et al., 2012), so $\geq 14 \mathrm{ng} \cdot \mathrm{L}^{-1}$ is considered abnormal. Plasma osmolality was analyzed at baseline, 0,8 and $22 \mathrm{~h}$ following exercise using vapor pressure osmometry (Vapro ${ }^{\circledR}$ 5520, Wescor, USA). Samples $(10 \mu \mathrm{L})$ were measured in duplicate or triplicate (if first two samples $>3 \mathrm{mmol} \cdot \mathrm{kg}^{-1}$ apart).

\section{Data Analysis}

Blood pressure and plasma volume responses were modeled for key parameters (e.g., nadir) before inferential analyses using contemporary recommendations (Hopkins et al., 2009). Area under the curve (AUC), as one such parameter for $\mathrm{PEH}$ and hypovolemia, was calculated using the $\mathrm{AUC}_{G}$ method outlined by Pruessner et al. (2003). The response parameters were used to answer the two distinct questions-effect of exercise type (i.e., Endurance vs. Intervals Legs $_{\text {) }}$ ) and of exercise limb (Intervals Legs $_{\text {vs. Intervals }}$ Arms $)$-using available spreadsheets (xPrePostCrossover.xls, at www.newstats.org). In determining the smallest clinical change thresholds for meaningful response magnitudes, a $1 \%$ change was used for plasma volume change (Convertino, 1983) and a $2 \mathrm{~mm} \mathrm{Hg}$ change for arterial blood pressure (Cook et al., 1995). For measurements with an unknown smallest clinical change threshold, the default value of 0.20 Cohen units was used. The probability that an outcome effect is positive, trivial or negative refers to whether it is clinically, practically or mechanistically meaningful (positive or negative) or not (trivial) (Hopkins, 2006). Comparisons of major interest are reported as mean differences with $95 \%$ confidence intervals, corrected to preclude trivial effects as described above. Paired $t$ tests were used for simple comparison between two experimental conditions (e.g., AUC), and two-way repeated measures ANOVA for time-dependent data (e.g., osmolality change). The ANOVAs 
were corrected for violations of sphericity using the Huynh-Feldt correction, and post-hoc comparisons were undertaken using the Bonferroni correction, using $\alpha=0.05$. Linear regression was used to explore the relation between the 22-h hypervolemic responses and the preceding $\mathrm{PEH}$.

\section{RESULTS}

All participants completed all familiarization, standardization and experimental procedures, except that Intervals exercise was truncated in 3 of 24 trials due to nausea caused by the intense exercise. Trials were separated by at least 8 days (normally 14) within participants. Results are given for the first research question (effect of exercise type; Endurance vs. Intervals Legs $_{\text {) }}$ before the second question (effect of limbs used; Intervals Legs $_{\text {vs. }}$ Intervals Arms $_{\text {). }}$.

\section{Blood Pressure Exercise Type}

The mean blood pressure profiles for different forms of exercise are shown in Table 1, and a typical profile of blood pressure (and plasma volume) responses is shown in Figure 2. The MAP was similar at baseline between Endurance and Intervals Legs $_{\text {s }}$ conditions $(p=0.68)$. The nadir of PEH occurred at similar time between exercise types $(p=0.88)$, and while there were on average differences for the hypotension magnitude and its duration (time to re-attain baseline), these were not statistically reliable ( $p \geq 0.26$, see Table 1 ). However, the volume of $\mathrm{PEH}$ (AUC) was almost twice as large for Intervals $_{\text {Legs }}$ as for Endurance (Table 1, and Figure 3 for individual responses; $p=0.05$ ). The probability that this difference was larger/trivial/smaller than for Endurance was $98 / 0 / 2 \%$, respectively. On the day after exercise ( $22 \mathrm{~h})$, MAP was $8 \pm 8 \mathrm{~mm} \mathrm{Hg}$ lower than baseline for Endurance $(p=0.01$; Figure 4), while Intervals $s_{\text {Legs }}$ showed no reliable change from baseline $(0 \pm 7 \mathrm{~mm} \mathrm{Hg} ; p=0.99)$. This $8 \mathrm{~mm} \mathrm{Hg}$ difference between conditions was significant ( $p=0.04, \mathrm{CI}: 8 \pm 7 \mathrm{~mm}$ $\mathrm{Hg}$ ), with the chance of the true effect for Endurance being beneficial/trivial/adverse as $95 / 4 / 1 \%$, respectively.

\section{Exercised Limbs}

At baseline, MAP was similar between the two Interval conditions ( $p=0.53$ ). On average, the nadir of the PEH occurred $\sim 30$ min earlier following intervals with arms than legs, but this difference was not significant $(p=0.12)$. The amplitude $(p=$ $0.14)$ and duration $(p=0.61)$ of hypotension were also not reliably different between conditions, and nor was its volume (AUC; Figure 3; $p=0.48$, CI for difference: -5157 to $2635 \mathrm{~mm}$ $\mathrm{Hg} \cdot \mathrm{min})$. The change in MAP from baseline to $22 \mathrm{~h}$ also showed an unclear effect between Intervals $s_{\text {Legs }}$ and Intervals Arms $_{\text {( }}(p=$ 0.20, CI: $-4 \pm 7 \mathrm{~mm} \mathrm{Hg}$, Figure 4).

\section{Plasma Volume \\ Exercise Type}

Following exercise, the amplitude of hypovolemia was $50 \%$ larger following Intervals Legs $_{\text {than }}$ Endurance $(p=0.02$, Table 1). Plasma volume returned through baseline earlier

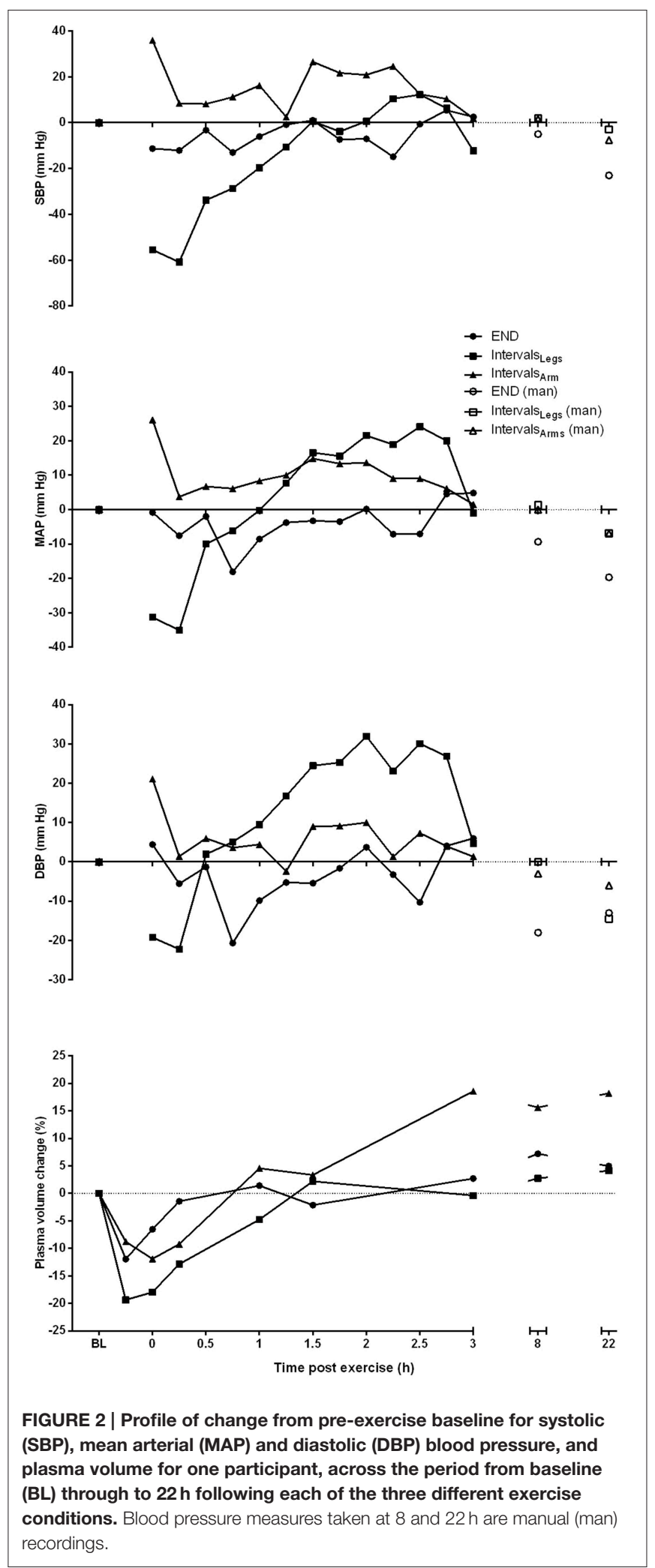

following Endurance $(p=0.04)$, so the volume of post-exercise hypovolemia (AUC) was $\sim 3$ fold larger for Intervals $(p<0.001)$; the chance of this difference being positive/trivial/ negative was 
TABLE 1 | Parameters of mean arterial pressure and plasma volume responses following endurance and interval exercise conditions.

\begin{tabular}{|c|c|c|c|c|c|}
\hline & Endurance & Intervals Legs & Intervals Arms & Mean $(95 \% \mathrm{Cl})$ for Intervals-Endurance & Mean $(95 \% \mathrm{Cl})$ for Legs-Arms \\
\hline \multicolumn{6}{|l|}{ MEAN ARTERIAL PRESSURE } \\
\hline Baseline (mm Hg) & $103(5)$ & $102(5)$ & $100(4)$ & & \\
\hline PEH nadir (h:min) & $1: 05(0: 59)$ & $1: 01(0: 55)$ & $0: 28(0: 35)$ & $-0: 06(0: 54)$ & $0: 36(0: 12)$ \\
\hline PEH amplitude (mm Hg) & $-17(12)$ & $-22(9)$ & $-14(16)$ & $-5(10)$ & $-8(11)$ \\
\hline PEH duration (h:min) & $1: 11(1: 43)$ & $1: 53(0: 58)$ & $1: 37(1: 39)$ & $-0: 42(1: 36)$ & $0: 18(1: 12)$ \\
\hline PEH AUC (mm Hg.min) & $3897(2757)$ & 7540 (3853) & $6420(3947)$ & 3392 (3372) & $-1261(3896)$ \\
\hline \multicolumn{6}{|l|}{ PLASMA VOLUME } \\
\hline Hypovolemia nadir (h:min) & $0: 13(0: 06)$ & $0: 18(0: 04)$ & $0: 21(0: 06)$ & $-0: 05$ (0:04) & $-0: 03(0: 04)$ \\
\hline Hypovolemia peak amplitude (\%) & $12(6)$ & $18(3)$ & $21(6)$ & $-6(4)$ & $-3(4)$ \\
\hline Hypovolemia duration (h:min) & $0: 15(0: 13)$ & $1: 11(1: 24)$ & $0: 49(0: 25)$ & $0: 54(0: 54)$ & $-0: 24(0: 54)$ \\
\hline $\mathrm{AUC}(\% \cdot \min )$ & $251(175)$ & $789(268)$ & $692(284)$ & $537(236)$ & $-97(237)$ \\
\hline
\end{tabular}

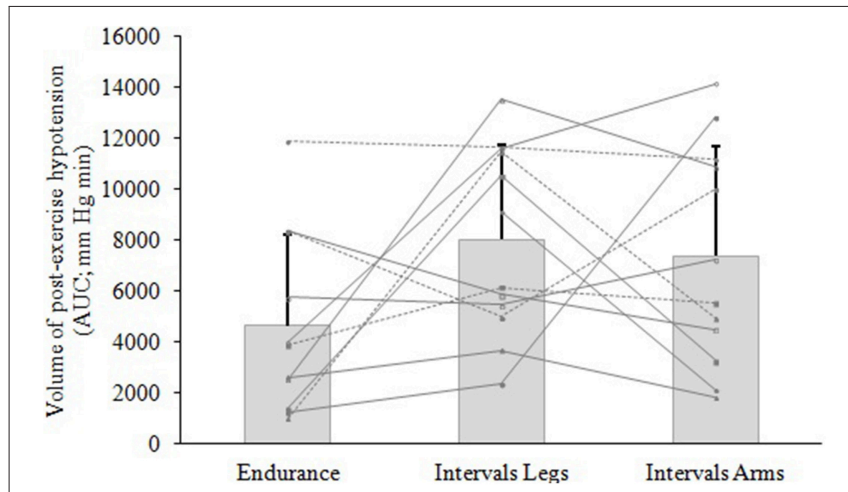

FIGURE 3 | Volume of hypotension following exercise of different type (Endurance, Intervals Legs $_{\text {) }}$ or different limbs used

(Intervals Legs or Arms). Data are mean \pm SD (bars) and individual responses (lines) of area under the curve (AUC) for the change in mean arterial pressure (MAP), for 12 participants. AUC is calculated from immediately following exercise until MAP returned through baseline.

$100 / 0 / 0 \%$, respectively. By the following day, plasma volume had increased by $5 \pm 5 \%$ for both modes of exercise (between condition effect, $p=0.87$ ). However, the progression of this rebound hypervolemia may have differed between conditions (see Figure 5).

\section{Exercised limbs}

Immediately following exercise the amplitude of hypovolemia did not differ reliably for Intervals performed with the Legs versus Arms $(p=0.12$, Table 1). Neither did its duration $(p=0.38)$ or volume (AUC: $p=0.38$ ). By $22 \mathrm{~h}$, plasma volume had increased $5 \pm 7 \%$ above baseline following Intervals Arms $_{\text {(Figure 5), which }}$ was comparable $(p=0.68)$ to that following Intervals Legs. $_{\text {s }}$.

Plasma, red cell and blood volumes at rest were $47.7 \mathrm{~mL} \cdot \mathrm{kg}^{-1}$ (SD: 4.7 ), $33.3 \mathrm{~mL} \cdot \mathrm{kg}^{-1}$ (SD: 3.8 ), and $80.9 \mathrm{~mL} \cdot \mathrm{kg}^{-1}$ (SD: 7.4 ), respectively. These absolute plasma and blood volumes were not predictive of the change in plasma volume following any exercise trial (all $r^{2} \leq 0.19$ ). Participants' maximal aerobic power was similarly not predictive of their change in plasma volume $\left(r=-0.33\right.$ for Endurance, -0.21 for Intervals Legs $_{\text {s }}$, and -0.24

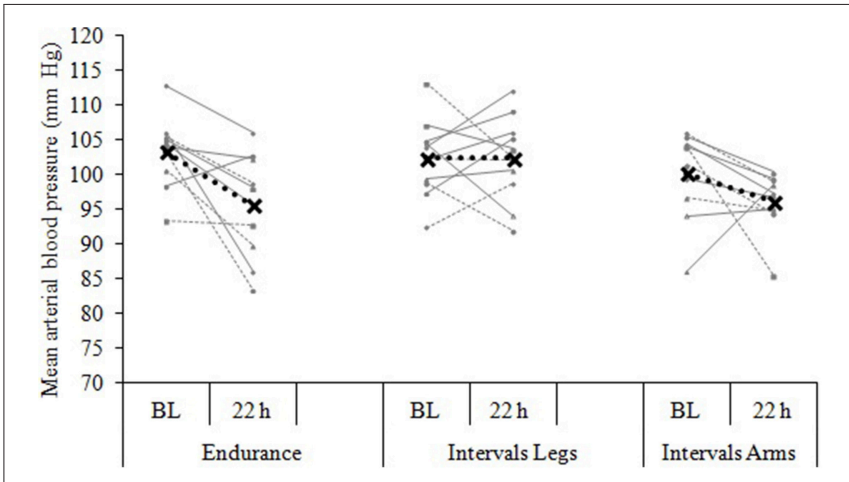

FIGURE 4 | Blood pressure change from baseline (BL) to $22 \mathrm{~h}$ following each of three exercise conditions. Data are the individual response (gray lines) and mean (black dashed line) of 12 participants, with all measures taken at the same time of day, in a standardized seated position.

for Intervals $\left.s_{A r m s}\right)$. As shown in Figure 6, the magnitude of $\mathrm{PEH}$ (AUC of mean arterial pressure) was modestly predictive of the change in plasma volume following Interval exercise (Intervals Legs $_{1}: r^{2}=0.19$; Intervals Legs $: r^{2}=0.29$ ), for which the threshold PEH in this cohort appeared to be an AUC of $\sim 2000 \mathrm{~mm} \mathrm{Hg} \mathrm{min}$. No such relation between $\mathrm{PEH}$ and change in plasma volume was evident following Endurance exercise $\left(r^{2}=0.004\right)$.

\section{Plasma Solutes (Table 2) \\ Exercise Type}

The time profiles of solute responses to exercise are shown in Table 2. All solutes showed elevated concentrations immediately after exercise (all $p<0.01$ ), but osmolality increased more across Interval than Endurance exercise, by $14 \mathrm{mOsmol} \cdot \mathrm{kg}^{-1}$ (interaction: $p<0.01$; CI: 6 to 21 ). Protein concentrations had recovered within $3 \mathrm{~h}$ following both types of exercise, whereas plasma osmolality showed more prolonged elevation following Intervals $_{\text {Legs, }}$, which at $22 \mathrm{~h}$, reflected less variability between individuals. 
Plasma cardiac TnT was elevated $\left(>14 \mathrm{ng} \cdot \mathrm{L}^{-1}\right)$ in $5 / 12$ participants within the 22-h study period after Endurance; in the range of 16 - $70 \mathrm{ng} \cdot \mathrm{L}^{-1}$, while no participant showed elevated TnT after Intervals $s_{\text {Legs. }}$. The mean difference in peak TnT between Endurance and Intervals ${ }_{\text {Legs }}$ was $11 \pm 13 \mathrm{ng} \cdot \mathrm{L}^{-1}$. The AUC of TnT elevation across the $22 \mathrm{~h}$ following exercise was larger (by $\left.5843 \mathrm{ng} \cdot \mathrm{L}^{-1} \cdot \mathrm{min}\right)$ for Endurance than for Intervals ${ }_{\text {Legs }}(p=0.04$; CI: 11476-209).

\section{Exercise Limbs}

Interval exercise using the legs or arms had comparable effects on the mean changes in total protein $(p=0.39)$ and albumin $(p=$ 0.44 ) concentrations, both acutely and at $22 \mathrm{~h}$ following exercise (Table 2). Plasma osmolality increased acutely by an average of $14 \mathrm{mOsmol} \cdot \mathrm{kg}^{-1}$ with Intervals Arms , which was two-thirds of the

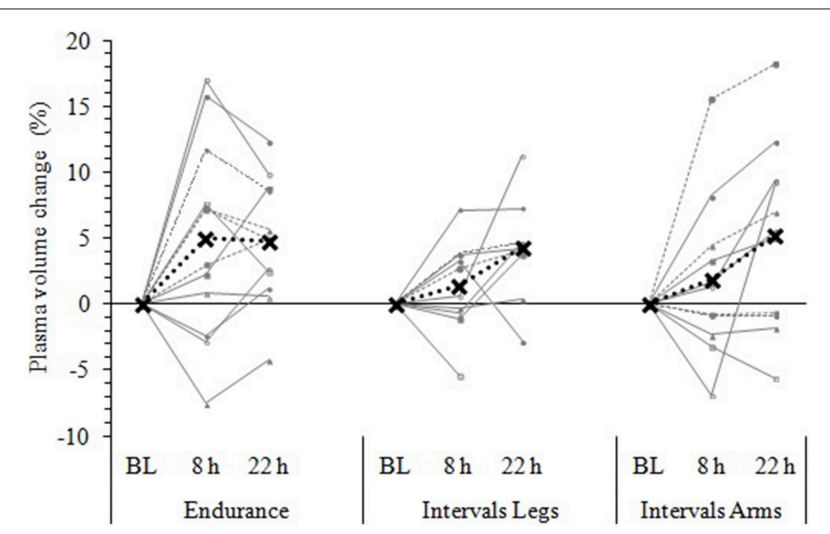

FIGURE 5 | Change in plasma volume from baseline (BL) to 8 and $22 \mathrm{~h}$ following each exercise condition. Data are the individual response (gray lines) and mean (black dashed line) of 12 participants, with all measures taken at the same time of day, in a standardized seated position, while fasted (BL and 22 h) or post prandial (8 h). Plasma volume change was measured via the hemoglobin-hematocrit method.

TABLE 2 | Plasma total protein and albumin concentrations before exercise (Baseline) and absolute change scores at 0,8 , and $22 \mathrm{~h}$ following exercise.

\begin{tabular}{|c|c|c|c|c|c|}
\hline & Baseline & $\Delta @ \mathbf{O h}$ & $\Delta @ 3 h$ & $\Delta @ 8 h$ & $\Delta$ @ $22 \mathrm{~h}$ \\
\hline \multicolumn{6}{|c|}{ PLASMA TOTAL PROTEIN $\left(\mathrm{g} \cdot \mathrm{L}^{-1}\right)$} \\
\hline Endurance & $73(6)$ & $7(3)^{*}$ & $2(6)$ & $4(7)$ & $-1(3)$ \\
\hline Intervals Legs $_{\text {L }}$ & $69(3)$ & $11(2)^{*}$ & $1(3)$ & $3(3)$ & $1(2)$ \\
\hline Intervals Arms & $70(4)$ & $12(2)^{*}$ & $3(3)$ & $2(8)$ & $2(4)$ \\
\hline \multicolumn{6}{|c|}{ PLASMA ALBUMIN $\left(g \cdot L^{-1}\right)$} \\
\hline Endurance & $48(4)$ & $4(2)^{*}$ & $1(4)$ & $2(3)$ & $0(2)$ \\
\hline Intervals Legs $_{\text {L }}$ & $46(1)$ & $6(1)^{*}$ & $1(1)$ & $2(2)$ & $1(1)$ \\
\hline Intervals Arms & $46(2)$ & $7(1)^{\star}$ & $2(2)$ & $2(4)$ & $1(2)$ \\
\hline \multicolumn{6}{|c|}{ PLASMA OSMOLALITY (mOsmol. $\left.\mathrm{kg}^{-1}\right)$} \\
\hline Endurance & $282(14)$ & $6(7)$ & - & $2(8)$ & $8(11)$ \\
\hline Intervals Legs $_{\text {L }}$ & $286(4)$ & $20(10)^{\star}$ & - & $8(7)^{*}$ & $5(4)^{*}$ \\
\hline Intervals Arms & $287(6)$ & $14(6)^{*}$ & - & $4(11)^{*}$ & $4(9)$ \\
\hline
\end{tabular}

Data are mean (SD) protein concentrations for $n=11$, and osmolality for $n=10$. ${ }^{*}$ Denotes $p<0.05$ from baseline. increase with Intervals $s_{\text {Legs }}$, but this was not a reliable difference ( $p=0.11, \mathrm{CI}:-6 \pm 7 \mathrm{mOsmol} \cdot \mathrm{kg}^{-1}$; chances of more/trivial/less difference $3 / 8 / 89 \%$, respectively).

Plasma concentration of cardiac TnT was not elevated $(>14$ $\left.\mathrm{ng} \cdot \mathrm{L}^{-1}\right)$ in any participant following Interval exercise of either the legs or arms. The mean difference in peak TnT between Intervals $_{\text {Legs }}$ and Intervals Arms $_{\text {was }} 2 \pm 2 \mathrm{ng} \cdot \mathrm{L}^{-1}(p=0.16)$. The TnT AUC across the $22 \mathrm{~h}$ following exercise did not differ according to which limbs were exercised (mean difference 634 ng. $\mathrm{L}^{-1} \cdot \min ; p=0.24$; CI: $\left.-1749-481\right)$. All TnT results were normal $(<14 \mathrm{ng} / \mathrm{L})$ by $22 \mathrm{~h}$.

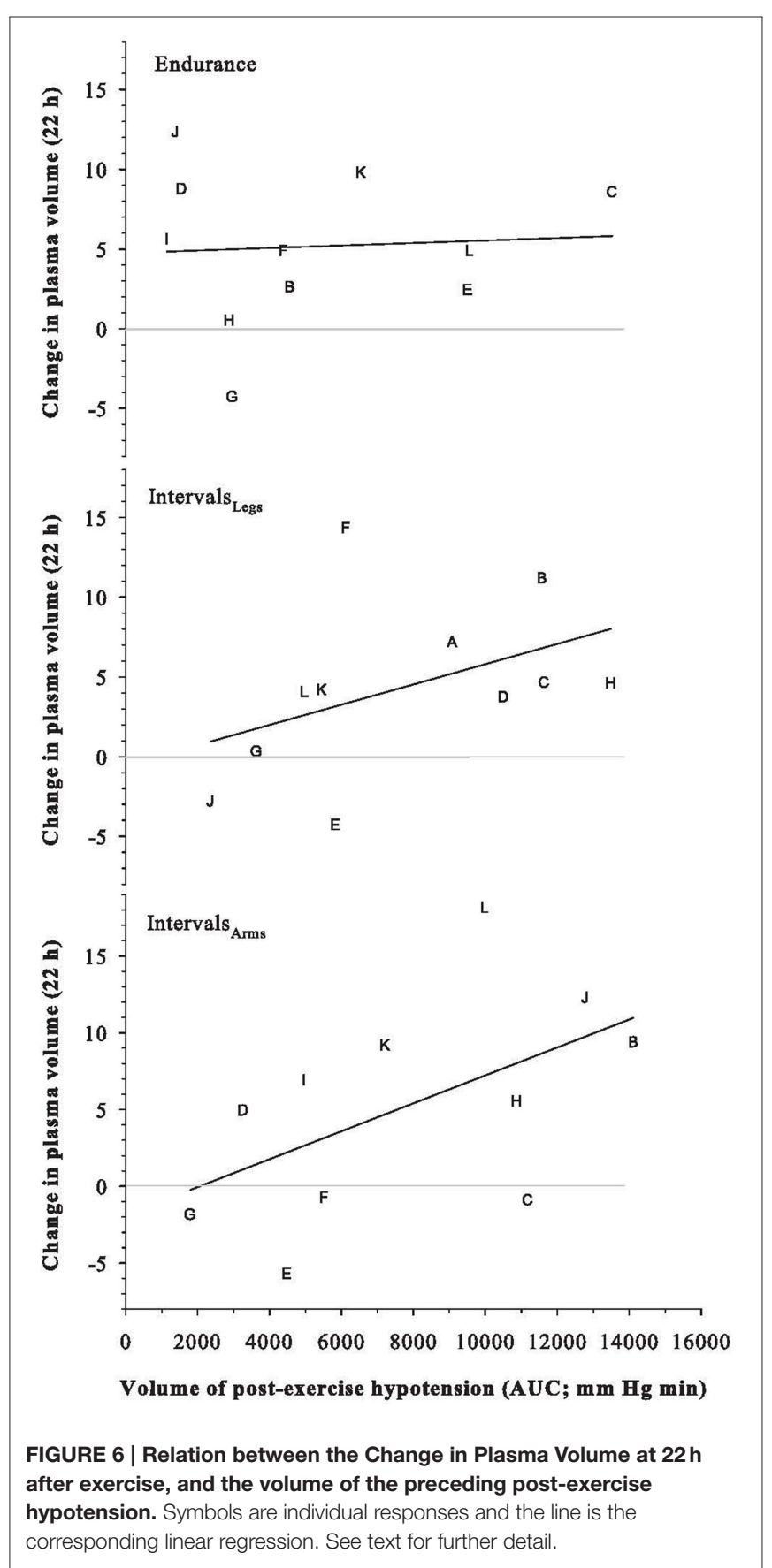




\section{DISCUSSION}

The main aim of the current study was to investigate the roles of exercise-intensity profile and exercised limbs on hemodynamics acutely $(<24 \mathrm{~h})$, because effects within this timeframe underpin both the adaptive responses and the daily dosage benefits of exercise. The main findings were that: (1) The volumes (AUC) of $\mathrm{PEH}$ and hypovolemia were more pronounced following brief maximal-effort exercise Intervals than Endurance exercise, despite much lower net duration of Intervals; (2) whereas, at $22 \mathrm{~h}$ after exercise, MAP was unchanged from baseline for Intervals but lowered for Endurance; (3) both forms of exercise stimulated plasma volume to expand by $5 \%$ in the first $22 \mathrm{~h}$, and; (4) the hemodynamic responses to Intervals were independent of whether it was performed with the arms or legs, despite their different muscle mass (and vascular capacity) and gravitational dependency. These findings therefore show different hypotensive profiles to the pattern of exercise but not to the limbs used, and show that similar improvements in blood (plasma) volume may be obtainable via a wide variety of moderate-to-severe intensity exercise with different muscle groups.

While blood pressure change and plasma volume expansion are discussed here as separate entities it is clear that they are interdependent. For example, at least some reduction in MAP following exercise appears to be a prerequisite stimulus to plasma volume expansion (Nagashima et al., 1999; Hayes et al., 2000), whereas during exercise the increase in ultrafiltration due to increased MAP and capillary hydrostatic pressure causes plasma volume to decrease and thereby has some effect on blood pressure (Holtzhausen and Noakes, 1995). The effects of exercise intensity and of exercised limbs are discussed concurrently here because that is more useful when considering the causation of PEH, early stage hypovolemia and rebound hypervolemia.

\section{Blood Pressure}

The current results indicate that while some specific parameters of the PEH are comparable for vastly different forms of exercise, the magnitude (AUC) seems much more dependent on the exercise intensity (and perhaps the consequently intermittent profile) than on its duration. The potency of high-intensity exercise is emphasized in that a total of just 2.5 min of maximaleffort exercise has more effect than a "typical" enduranceintensity exercise bout of $\sim 5$ times the energy usage and $\sim 10$ times the net duration ( $\sim 2$ times the gross duration). While others have found comparable rather than larger effects of such Intervals when compared with sustained exercise at moderate intensity (Rossow et al., 2010; Lacombe et al., 2011), all findings support the basic notion that sprint-interval exercise impacts $\mathrm{PEH}$ disproportionately to the additional intensity.

We observed similar magnitudes of acute PEH between upper- and lower-body ergometry at matched relative (maximaleffort) workloads. Similar results were obtained by MacDonald et al. (2000) for PEH following 30-min arm ergometry at 65\% and leg ergometry at $70 \%$ limb-specific $\mathrm{V}_{2}$ max in borderline hypertensive individuals, and by de Almeida et al. (2010) for PEH following incremental arm ergometry vs. leg ergometry to exhaustion. The current study adds to the sparse literature on this issue of limb dependency, and shows that the substantive effects on PEH are obtainable from only $2.5 \mathrm{~min}$ of net/effective effort.

The comparable changes in PEH after both Intervals $\mathrm{Legs}_{\mathrm{L}}$ and Intervals $s_{A r m s}$ support Halliwill et al. (2013) in indicating that PEH appears to be mediated at least partly by inhibition of central sympathetic vasoconstrictor output rather than solely through a sustained vasodilation of previously active vasculature. Systemic vascular resistance has been found to be reduced for $1 \mathrm{~h}$ following a maximal graded cycling test (Coats et al., 1989). This concurs with evidence that factors within the central nervous system [substance P (neurotransmitter) and GABAergic (major cardiovascular sympathetic inhibitor)] may be contributors to both the exercise pressor response and PEH (Chen and Bonham, 2010). The marked and consistent finding whereby maximal-effort arm exercise elicits PEH as powerfully as that obtained from higher-volume leg exercise reinforces contemporary understandings of PEH. That is, muscle chemoreceptors are thought to act via the NTS to inhibit sympathetically-mediated vascular constriction, which means that PEH is not dependent on the muscle mass or on its gravitational dependency.

At $22 \mathrm{~h}$ following Endurance, MAP was on average $8 \pm$ $8 \mathrm{~mm} \mathrm{Hg}$ lower than at baseline, while Intervals showed no change from baseline irrespective of whether the exercise had been performed with the lower or upper limb (Figure 4). The lack of a decreased MAP at $22 \mathrm{~h}$ following Intervals could potentially be due to a longer recovery time course of the sympathetic nervous system due to the higher exercise intensity. Of note, Goto et al. (2003) observed an improvement in endothelial function after moderate-intensity training, which did not change oxidative stress markers, whereas high-intensity training increased oxidative stress with no change in endothelial function. These authors concluded that the impact of exercise on endothelial function may be dependent on the balance between reactive oxygen species, antioxidant defenses, and their impact on nitric oxide availability (Goto et al., 2003). Similarly, lessfavorable shear stress profiles (i.e., if more retrograde flow) during the exercise session may have attenuated endothelial function due to increased sympathetic constriction in arterioles within vasculature beds outside of active muscle. Therefore, in the current study the higher exercise intensity may have caused excessive oxidative stress or less favorable shear stress profiles and therefore inhibited improvements in endothelial function at $22 \mathrm{~h}$.

Delayed effects of exercise on arterial pressures are important for healthy and hypertensive individuals, and the current findings add to a conflicting literature on this issue. For example, supportive but also contrasting findings have been shown in regard to effects of both sustainable exercise and sprint interval training. Forjaz et al. (2004) found no reduction in MAP at $22 \mathrm{~h}$ following $45 \mathrm{~min}$ of cycling at either 30,50 , or $75 \% \dot{\mathrm{V}}_{2}$ max in normotensive males and females; nor did Wallace et al. (1999) following $50 \mathrm{~min}$ of intermittent walking $(5 \times 10 \mathrm{~min}$ with $3 \mathrm{~min}$ rest periods) at $50 \% \mathrm{VO}_{2}$ max in normotensive males and females $22 \mathrm{~h}$ following exercise. Whereas, 2 weeks of sprint interval training using a protocol similar to the one 
used here, led to meaningful reductions in systolic $(-6 \mathrm{~mm}$ $\mathrm{Hg})$ and diastolic $(-9 \mathrm{~mm} \mathrm{Hg})$ pressures at $24 \mathrm{~h}$ after the final (6th) session of intervals (Whyte et al., 2010). Irrespective, it is worth noting that the more common, clinical-model of high intensity interval training, involving longer and lower-intensity intervals (1-4 min of exercise to $85-95 \% \mathrm{HR}_{\max }, 1-3$ min apart), seems to show more consistent reductions in arterial pressures (Molmen-Hansen et al., 2012; Ronnestad et al., 2014; Wisløff et al., 2015).

\section{Plasma Volume Expansion}

The 5\% expansion of plasma volume that was evident $22 \mathrm{~h}$ following both Endurance and Intervals Legs $_{\text {is }}$ consistent with those observed (5-7\%) in studies from the John B Pierce laboratory, using a more clinically-acceptable/relevant model of interval exercise [i.e., $8 \times 4$-min intervals at $85 \% \dot{\mathrm{VO}}_{2}$ max; (Gillen et al., 1994; Haskell et al., 1997; Yang et al., 1998; Nagashima et al., 1999, 2000)]. Surprisingly, we also observed a similar 5\% plasma volume expansion with Intervals $\mathrm{Arms}_{\mathrm{A}}$ at $22 \mathrm{~h}$ following exercise. While unexpected, the mechanisms by which they may have occurred seem plausible and unsurprising in retrospect. Despite the differences in muscle mass activation, both stimulated similar post-exercise hypovolemia and hypotension [i.e., presumably in response to afferent input from muscle exercise at matched and maximal relative intensity (Miles et al., 1983)]. This similar hypotensive response would presumably facilitate an expansion of plasma volume via increased renal reabsorption of sodium and increased albumin content due to increased return lymphatic return to the circulation and synthesis, and reduced loss of albumin (Gillen et al., 1994; Haskell et al., 1997; Yang et al., 1998; Nagashima et al., 1999, 2000).

However, the causal link between $\mathrm{PEH}$ and subsequent expansion of plasma volume (measured at $22 \mathrm{~h}$ ) is presumably not this straight forward, because the three-fold larger $\mathrm{PEH}$ in Interval exercise yielded a hypervolemic response of equivalent magnitude to that from Endurance exercise, and the participants experiencing larger or smaller $\mathrm{PEH}$ did not show a correspondingly larger or smaller hypervolemic response. Neither did their hypervolemic response depend on their baseline blood volume or blood pressure. Some independence thus exists between $\mathrm{PEH}$ and subsequent plasma volume expansion. In an attempt to explain this, the differences in the time courses of change seem an important factor. A possible mechanism underlying these different time course profiles is AVP activity and its release in response to exercise intensity. Scott et al. (1997) found AVP levels not to be elevated during $50 \mathrm{~min}$ of running at 25 or $45 \% \dot{\mathrm{VO}}_{2}$ max, whereas it was elevated with running at $65 \% \dot{\mathrm{VO}}_{2}$ max. Based on these findings it is possible that the Interval exercise in the current study stimulated a larger and more prolonged AVP release due to the higher exercise intensity and disruption of homeostasis. Interval exercise led to a smaller expansion in plasma volume (Figure 5) and increased osmolality (Table 2) compared to Endurance at $8 \mathrm{~h}$. These two key mediators of AVP release indicate that AVP levels may have been elevated to a higher level and for longer following Interval exercise. These potentially elevated levels of AVP might also help explain the lack of MAP change from baseline at $22 \mathrm{~h}$ for both Interval exercise conditions compared with Endurance, as well as the different trends in plasma volume expansion that seem evident at $22 \mathrm{~h}$. While the half-life of AVP and plasma renin activity are 5 and 20 min respectively (Convertino et al., 1980), it is possible that a prolonged release of these hormones is stimulated due to the greater disruption of homeostasis following Intervals, causing a plasma volume expansion greater than what was measured in the current study past the $22 \mathrm{~h}$ time point. Future research could profile a longer period of post-exercise response to address this speculation.

\section{Troponin T Release}

These data indicate that TnT may be released in many (but not all) healthy, sedentary individuals following endurance exercise of moderate duration and intensity. The absence of a TnT elevation following repeated 30 -s interval exercise was unexpected, but adds support to the notion that duration of exercise may be more consequential than intensity (Shave et al., 2007; Dawson et al., 2008). However, high-intensity exercise (30 min running, 85-90\% نंO2 max) of a different profile than utilized in this study has elicited TnI elevation in some participants (Shave et al., 2010), so volume of exercise is perhaps a more relevant parameter. The patterns of release were nonuniform and not able to be related to specific demographics or exercise data. Further research is required to explore the differential responses and the specific parameters of exercise that induce troponin release.

\section{Limitations}

This study is subject to several limitations. Except for the initial $3 \mathrm{~h}$ of laboratory-based monitoring, dietary standardization and activity guidelines, in other respects the post-exercise period was carried out in a relatively free-living environment. It is acknowledged that this free-living environment could have potentially influenced the results at the 8 and $22 \mathrm{~h}$ measurement times even with the standardizations. However, it was seen as important to include this free living in the current study to increase the robustness of findings to real-world settings. The study was also limited to male participants due to time constraints on the study duration, given that only one trial would be possible within each menstrual cycle. It cannot be assumed that these results apply to females even within the follicular phase, because of the numerous effects of estrogen and progesterone on central and peripheral (renal and vascular) mechanisms of fluid regulation, and on net effects of oxidative stress, for example. Studies that have compared effects of Intervals and/or Endurance exercise in females and males have found no difference in the net $\mathrm{PEH}$ in fit individuals, although underlying causation may differ between sexes (Rossow et al., 2010; Cote et al., 2015). Furthermore, the current findings indicate the involvement of the central nervous, anti-diuretic and renin angiotensin systems in the $\mathrm{PEH}$ response without the direct measurements of these.

\section{Perspectives and Summary}

The results of the current study indicate the importance of exercise intensity in stimulating acute $\mathrm{PEH}$. Of note, performing Intervals with the lower limbs caused similar post-exercise 
hypotensive and hypovolemic responses to those following Intervals with the upper limbs, emphasizing the integrative causation of $\mathrm{PEH}$, the mechanisms of which have been elucidated by others (e.g., Chen and Bonham, 2010; Halliwill et al., 2013). Furthermore, at $22 \mathrm{~h}$ following exercise, MAP had decreased below baseline values for Endurance but not for Intervals $s_{\text {Legs }}$, whereas the similarities between lower- and upperlimb exercise were still evident (i.e., neither had reliably caused a longer-term hypotension). These findings indicate that the recovery profiles following Intervals may be different, potentially due to prolonged elevation of sympathetic nervous system activity, elevated circulating stress hormones, or autocrine factors suppressing endothelial function. Importantly, all conditions stimulated a similar 5\% expansion of plasma volume by $22 \mathrm{~h}$ following exercise. These findings collectively allow a better comprehension of the short-term training response to different exercise stimuli, along with providing evidence for the use of a variety of exercise regimes that could be used by different populations (hypertensive, time constrained, paraplegic) to access the cardiovascular health benefits exercise provides. They also indicate that while Intervals have been shown to have very high metabolic value compared to Endurance, the effects of Intervals on long term blood pressure control maybe not as effective, yet this is equivocal (Whyte et al., 2010). Finally, the marked inter-individual variability in recovery responses following these somewhat polarized forms of exercise-whereby

\section{REFERENCES}

Burgomaster, K., Howarth, K., Phillips, S., Rakobowchuk, M., Macdonald, M., Mcgee, S., et al. (2008). Similar metabolic adaptations during exercise after low volume sprint interval and traditional endurance training in humans. J. Physiol. 586, 151-160. doi: 10.1113/jphysiol.2007.142109

Chaplin, H., and Mollison, P. (1952). Correction for plasma trapped in the red cell column of the hematocrit. Blood 7, 1227-1238.

Chaplin, H., Mollison, P., and Vetter, H. (1953). The body/venous hematocrit ratio: its constancy over a wide hematocrit range. J. Clin. Invest. 32, 1309-1316. doi: 10.1172/JCI102859

Chen, C., and Bonham, A. (2010). Postexercise hypotension: central mechanisms. Exerc. Sport. Sci. Rev. 38, 122-127. doi: 10.1097/JES.0b013e3181e372b5

Coats, A., Conway, J., Isea, J., Pannarale, G., Sleight, P., and Somers, V. (1989). Systemic and forearm vascular resistance changes after upright bicycle exercise in man. J. Physiol. 413, 289-298. doi: 10.1113/jphysiol.1989.sp017654

Convertino, V. (1983). Heart rate and sweat rate responses associated with exercise-induced hypervolemia. Med. Sci. Sports Exerc. 15, 77-82. doi: 10.1249/00005768-198315010-00014

Convertino, V., Brock, P., Keil, L., Bernauer, E., and Greenleaf, J. (1980). Exercise training-induced hypervolemia: role of plasma albumin, renin, and vasopressin. J. Appl. Physiol. 48, 665-669.

Cook, N., Cohen, J., Hebert, P., Taylor, J., and Hennekens, C. (1995). Implications of small reductions in diastolic blood pressure for primary prevention. Arch. Intern. Med. 155, 701-709. doi: 10.1001/archinte.1995.00430070053006

Cote, A. T., Bredin, S. S., Phillips, A. A., Koehle, M. S., and Warburton, D. E. (2015). Greater autonomic modulation during post-exercise hypotension following high-intensity interval exercise in endurance-trained men and women. Eur. J. Appl. Physiol. 115, 81-89. doi: 10.1007/s00421-014-2996-5

Dawson, E. A., Whyte, G. P., Black, M. A., Jones, H., Hopkins, N., Oxborough, D., et al. (2008). Changes in vascular and cardiac function after prolonged strenuous exercise in humans. J. Appl. Physiol. (1985) 105, 1562-1568. doi: 10.1152/japplphysiol.90837.2008 some individuals even showed larger PEH to Endurance than Intervals-further highlights the need for personalized rather than blanket prescription of exercise (MacDonald et al., 2000; Rossow et al., 2010; Lacombe et al., 2011; Luttrell and Halliwill, 2015). While this study used exercise profiles known to be effective in improving fitness, for reasons of safety and acceptance (e.g., avoiding nausea) it would be important to avoid starting training at these session volumes.

\section{AUTHOR CONTRIBUTIONS}

All authors contributed meaningfully to the four contribution criteria. Authors taking lead roles in each phase were: JC for conception of the study, obtaining funding and ethics approvals, and supervising the project; MG for extensive planning of the study, participant recruitment, data collection and analysis, and writing the first draft of the manuscript. MF, SS, and EP assisted extensively in data collection, and SL co-supervised the project through all phases.

\section{FUNDING}

This study received funding support from the School of Physical Education, Sport, and Exercise Sciences and a University of Otago Research Grant.

de Almeida, W. S., de Jesus Lima, L. C., da Cunha, R. R., Simbers, H. G., Nakamura, F. Y., and Campbell, C. S. (2010). Post-exercise blood pressure responses to cycle and arm-cranking. Sci. Sports 25, 74-80. doi: 10.1016/j.scispo.2009. 09.001

de Feo, P., Horber, F. F., and Haymond, M. W. (1992). Meal stimulation of albumin synthesis: a significant contributor to whole body protein synthesis in humans. Am. J. Physiol. 263(4 Pt 1), E794-E799.

Eicher, J. D., Maresh, C. M., Tsongalis, G. J., Thompson, P. D., and Pescatello, L. S. (2010). The additive blood pressure lowering effects of exercise intensity on post-exercise hypotension. Am. Heart J. 160, 513-520. doi: 10.1016/j.ahj.2010.06.005

Forjaz, C., Cardoso, C., Rezek, C., Santaella, D., and Tinucci, T. (2004). Postexercise hypotension and hemodynamics: the role of exercise intensity. J. Sports Med. Phys. Fitness 44, 54-62.

Gibala, M., Little, J., Van Essen, M., Wilkin, G., Burgomaster, K., Safdar, A., et al. (2006). Short-term sprint interval versus traditional endurance training: similar initial adaptations in human skeletal muscle and exercise performance. J. Physiol. 575, 901-911. doi: 10.1113/jphysiol.2006.112094

Gibala, M., and Mcgee, S. L. (2008). Metabolic adaptations to short-term highintensity interval training: a little pain for a lot of gain? Exerc. Sport Sci. Rev. 36, 58-63. doi: 10.1097/JES.0b013e318168ec1f

Gillen, C. M., Nishiyasu, T., Langhans, G., Weseman, C., Mack, G. W., and Nadel, E. R. (1994). Cardiovascular and renal function during exercise-induced blood volume expansion in men. J. Appl. Physiol. 76, 2602-2610.

Goto, C., Higashi, Y., Kimura, M., Noma, K., Hara, K., Nakagawa, K., et al. (2003). Effect of different intensities of exercise on endothelium-dependent vasodilation in humans. Role of endothelium-dependent nitric oxide and oxidative stress. Circulation 108, 530-535. doi: 10.1161/01.CIR.0000080893. 55729.28

Halliwill, J. R., Buck, T. M., Lacewell, A. N., and Romero, S. A. (2013). Postexercise hypotension and sustained postexercise vasodilatation: what happens after we exercise? Exp. Physiol. 98, 7-18. doi: 10.1113/expphysiol.2011. 058065 
Haskell, A., Nadel, E. R., Stachenfeld, N. S., Nagashima, K., and Mack, G. W. (1997). Transcapillary escape rate of albumin in humans during exercise-induced hypervolemia. J. Appl. Physiol. 83, 407-413.

Hayes, P., Lucas, J., and Shi, X. (2000). Importance of post-exercise hypotension in plasma volume restoration. Acta Physiol. Scand. 169, 115-124. doi: 10.1046/j.1365-201x.2000.00728.x

Holtzhausen, L., and Noakes, T. (1995). The prevalence and significance of postexercise (postural) hypotension in ultramarathon runners. Med. Sci. Sports Exerc. 27, 1595-1601. doi: 10.1249/00005768-199512000-00003

Hopkins, W. (2006). Spreadsheets for Analysis of Controlled Trials, with Adjustment for a Subject Charateristic. Available online at: http://www.sportsci.org

Hopkins, W. G., Marshall, S. W., Batterham, A. M., and Hanin, J. (2009). Progressive statistics for studies in sports medicine and exercise science. Med. Sci. Sports Exerc. 4, 3-13. doi: 10.1249/MSS.0b013e31818cb278

Jones, H., George, K., and Edwards, B. (2007). Is the magnitude of acute postexercise hypotension mediated by exercise intensity or total work done? Eur. J. Appl. Physiol. 102, 33-40. doi: 10.1007/s00421-007-0562-0

Lacombe, S. P., Goodman, J. M., Spragg, C. M., Liu, S., and Thomas, S. G. (2011). Interval and continuous exercise elicit equivalent postexercise hypotension in prehypertensive men, despite differences in regulation. Appl. Physiol. Nutr. Metab. 36, 881-891. doi: 10.1139/h11-113

Luttrell, M. J., and Halliwill, J. R. (2015). Recovery from exercise: vulnerable state, window of opportunity, or crystal ball? Front. Physiol. 6:204. doi: 10.3389/fphys.2015.00204

MacDonald, J. R., Macdougall, J. D., and Hogben, C. D. (2000). The effects of exercising muscle mass on post exercise hypotension. J. Hum. Hypertens. 14, 317-320. doi: 10.1038/sj.jhh.1000999

Middleton, N., George, K., Whyte, G., Gaze, D., Collinson, P., and Shave, R. (2008). Cardiac troponin $\mathrm{T}$ release is stimulated by endurance exercise in healthy humans. J. Am. Coll. Cardiol. 52, 1813-1814. doi: 10.1016/j.jacc.2008.03.069

Miles, D., Sawka, M., Glaser, R., and Petrofsky, J. (1983). Plasma volume shifts during progressive arm and leg exercise. J. Appl. Physiol. 54, 491-495.

Molmen-Hansen, H. E., Stolen, T., Tjonna, A. E., Aamot, I. L., Ekeberg, I. S., Tyldum, G. A., et al. (2012). Aerobic interval training reduces blood pressure and improves myocardial function in hypertensive patients. Eur. J. Prev. Cardiol. 19, 151-160. doi: 10.1177/1741826711400512

Nagashima, K., Cline, G. W., Mack, G. W., Shulman, G. I., and Nadel, E. R. (2000). Intense exercise stimulates albumin synthesis in the upright posture. J. Appl. Physiol. 88, 41-46.

Nagashima, K., Mack, G., Haskell, A., Nishiyasu, T., and Nadel, E. (1999). Mechanism for the posture-specific plasma volume increase after a single intense exercise protocol. J. Appl. Physiol. 86, 867-873.

Okazaki, K., Ichinose, T., Mitono, H., Chen, M., Masuki, S., Endoh, H., et al. (2009a). Impact of protein and carbohydrate supplementation on plasma volume expansion and thermoregulatory adaptation by aerobic training in older men. J. Appl. Physiol. 107, 725-733. doi: 10.1152/japplphysiol.912 65.2008

Okazaki, K., Ichinose, T., Mitono, H., Chen, M., Masuki, S., Endoh, H., et al. (2009b). Protein and carbohydrate supplementation after exercise increases plasma volume and albumin content in older and young men. J. Appl. Physiol. 107, 125-733. doi: 10.1152/japplphysiol.91264.2008

Pickering, T., Hall, J., Appel, L., Falkner, B., Graves, J., Hill, M., et al. (2005). Recommendations for blood pressure measurement in humans and experimental animals. Circulation 111, 697-716. doi: 10.1161/01.CIR.0000154900.76284.F6

Pruessner, J., Kirschbaum, C., Meinlschmid, G., and Hellhammer, D. (2003). Two formulas for computation of the area under the curve represent measures of total hormone concentration verse time-dependent change. Psychoneuroendocrinology 28, 916-931. doi: 10.1016/S0306-4530(02) 00108-7

Rakobowchuk, M., Tanguay, S., Burgomaster, K. A., Howarth, K. R., Gibala, M. J., and Macdonald, M. J. (2008). Sprint interval and traditional endurance training induce similar improvements in peripheral arterial stiffness and flow-mediated dilation in healthy humans. Am. J. Physiol. Regul. Integr. Comp. Physiol. 295, R236-R242. doi: 10.1152/ajpregu.00069.2008

Ronnestad, B. R., Hansen, J., and Ellefsen, S. (2014). Block periodization of highintensity aerobic intervals provides superior training effects in trained cyclists. Scand. J. Med. Sci. Sports 24, 34-42. doi: 10.1111/j.1600-0838.2012.01485.x

Rossow, L., Yan, H., Fahs, C. A., Ranadive, S. M., Agiovlasitis, S., Wilund, K. R., et al. (2010). Postexercise hypotension in an endurance-trained population of men and women following high-intensity interval and steady-state cycling. Am. J. Hypertens. 23, 358-367. doi: 10.1038/ajh.2009.269

Sawka, M. N., Convertino, V. A., Eichner, E. R., Schnieder, S. M., and Young, A. J. (2000). Blood volume: importance and adaptations to exercise training, environmental stresses, and trauma/sickness. Med. Sci. Sports Exerc. 32, 332-348. doi: 10.1097/00005768-200002000-00012

Schmidt, W., and Prommer, N. (2005). The optimised CO-rebreathing method: a new tool to determine total haemoglobin mass routinely. Eur. J. Appl. Physiol. 95, 486-495. doi: 10.1007/s00421-005-0050-3

Scott, M., Laird, J., Latzka, W., and Sawka, M. (1997). Aldosterone and vasopressin responses in the heat: hydration level and exercise intensity effects. Med. Sci. Sports Exerc. 29, 661-668. doi: 10.1097/00005768-199705000-00012

Shave, R., George, K., Atkinson, G., Hart, E., Middleton, N., Whyte, G., et al. (2007). Exercise-induced cardiac troponin T release: a meta-analysis. Med. Sci. Sports Exerc. 39, 2099-2106. doi: 10.1249/mss.0b013e318153ff78

Shave, R., Ross, P., Low, D., George, K., and Gaze, D. (2010). Cardiac troponin I is released following high-intensity short-duration exercise in healthy humans. Int. J. Cardiol. 145, 337-339. doi: 10.1016/j.ijcard.2009.12.001

Shave, R., Whyte, G., George, K., Gaze, D., and Collinson, P. (2005). Prolonged exercise should be considered alongside typical symptoms of acute myocardial infarction when evaluating increases in cardiac troponin T. Heart 91, 1219-1220. doi: 10.1136/hrt.2004.046052

SPARC (2008). Sport, Recreation and Physical Activity Participation among New Zealand Adults. (Wellington: Sparc).

Strauss, M., Davis, R., Rosenbaum, J., and Rossmeisl, E. (1951). "Water diuresis" produced during recumbency by the intravenous infusion of isotonic saline solution. J. Clin. Invest. 30, 862-868. doi: 10.1172/JCI102501

Thygesen, K., Alpert, J. S., Jaffe, A. S., Simoons, M. L., Chaitman, B. R., White, H. D., et al. (2012). Third universal definition of myocardial infarction. Eur. Heart J. 33, 2551-2567. doi: 10.1093/eurheartj/ehs184

Tucker, J. M., Welk, G. J., and Beyler, N. K. (2011). Physical activity in U.S.: adults compliance with the physical activity guidelines for Americans. Am. J. Prev. Med. 40, 454-461. doi: 10.1016/j.amepre.2010.12.016

Wallace, J., Bogle, P., King, B., Krasnoff, C., and Jastremski, C. (1999). The magnitude and duration of ambulatory blood pressure reduction following acute exercise. J. Hum. Hypertens. 13, 361-366. doi: 10.1038/sj.jhh.1000797

Whyte, L. J., Gill, J. M., and Cathcart, A. J. (2010). Effect of 2 weeks of sprint interval training on health-related outcomes in sedentary overweight/obese men. Metabolism 59, 1421-1428. doi: 10.1016/j.metabol.2010.01.002

Wisløff, U., Coombes, J. S., and Rognmo, Ø. (2015). CrossTalk proposal: high intensity interval training does have a role in risk reduction or treatment of disease. J. Physiol. 593, 5215-5217. doi: 10.1113/JP271041

Yang, R. C., Mack, G. W., Wolfe, R. R., and Nadel, E. R. (1998). Albumin synthesis after intense intermittent exercise in human subjects. J. Appl. Physiol. 84, 584-592.

Conflict of Interest Statement: The authors declare that the research was conducted in the absence of any commercial or financial relationships that could be construed as a potential conflict of interest.

Copyright (c) 2016 Graham, Lucas, Francois, Stavrianeas, Parr, Thomas and Cotter. This is an open-access article distributed under the terms of the Creative Commons Attribution License (CC BY). The use, distribution or reproduction in other forums is permitted, provided the original author(s) or licensor are credited and that the original publication in this journal is cited, in accordance with accepted academic practice. No use, distribution or reproduction is permitted which does not comply with these terms. 